Article

\title{
Sulfur and Oxygen Effects on High-Si Ductile Iron Casting Skin Formation
}

\author{
Denisa Anca, Mihai Chisamera, Stelian Stan, Iuliana Stan * and Iulian Riposan
}

Materials Science and Engineering Faculty, Politehnica University of Bucharest, 313 Spl. Independentei, 060042 Bucharest, Romania; denisa_elena.anca@upb.ro (D.A.); chisameramihai@gmail.com (M.C.); constantin.stan@upb.ro (S.S.); iulian.riposan@upb.ro (I.R.)

* Correspondence: iuliana.stan@upb.ro

Received: 27 May 2020; Accepted: 27 June 2020; Published: 29 June 2020

\begin{abstract}
The main objective of the present paper is to evaluate by thermal (cooling curve) analysis the solidification pattern and the occurrence of the layer of degenerate graphite at the surface of ductile iron castings (3.15\% Si, typically as 450-18 grade, ISO 1563/2011), with or without a mold coating, including $\mathrm{S}$ or $\mathrm{O}$, and different agents (carbonic material, iron powder), supposed to act to block their diffusion into the iron melt. It is found that the mold coating materials temperately influence the parameters of the solidification cooling curves and, more visibly, the occurrence and the thickness of the undesired skin layer. Different graphite morphologies comparable to the casting body are present, at a large range of thicknesses, from 50 up to $200 \mu \mathrm{m}$. The sulfur presence in the mold coating will promote a higher skin thickness compared to oxygen (up to $50 \%$ by oxygen and $2.5-3.3$ times for sulfur action), despite the fact that in the casting body, the graphite nodularity undergoes a limited decrease (from $85 \%$ up to $82 \%-83 \%$ level). Carbonic material or iron powder supplementary addition decreases these undesired effects, but the solidification undercooling compared to the equilibrium system is increased. It is found that carbonic material is more efficient at limiting oxygen than iron powder is at limiting the negative effects of sulfur on the casting skin thickness. More experiments are necessary to quantify their capacity to block the oxygen or sulfur transfer into the iron melt.
\end{abstract}

Keywords: thermal analysis; solidification cooling curves; eutectic undercooling; ductile cast iron; mold coating; sulfur; oxygen; degenerated graphite surface layer; structure

\section{Introduction}

Ceramic molds, used in metal castings production, are usually coated in order to control the metal-mold chemical interaction and to decrease the casting surface roughness. In Mg-treated iron castings, the coating is also important to control the graphite degeneration process in the surface layer. The surface layer with degenerated graphite causes stress raisers in the casting, similar to a notch, so all the mechanical properties are reduced. In a technical literature review, Boonmee and Stefanescu [1] found that the yield strength and elongation of cast ductile iron samples lied below the ASTM standard line, and only after machining, a significant number of samples lied above the standard, as the casting skin was removed. The casting skin effect on fatigue properties is expected to be more pronounced than the static properties because in thin-wall ductile iron castings, a reduction of $16.3 \%$ in the fatigue strength is observed. A deleterious effect of the casting skin in compacted graphite iron casting is also identified, suggesting that both the graphite degradation layer and surface roughness were responsible for the reduction in tensile properties.

The applied coating on the active surface of the mold in order to improve the casting surface quality also influences the solidification characteristics of the casting body and graphite degeneration in the casting surface layer (skin formation). These mold coatings will favor skin formation, in the 
presence of available sulfur or oxygen, to diffuse into the surface iron melt layer. Contrarily, inorganic materials expected to act as desulphurization items $\left(\mathrm{Al}_{2} \mathrm{O}_{3}, \mathrm{CaCO}_{3}\right.$, basic slag, $\mathrm{CaF}_{2}$, Talc, $\left.\mathrm{Mg}\right)$ are favorable for decreasing skin thickness [1-7].

In previous experiments [8-13], the graphite degeneration process in the surface layer of Mg-treated iron castings ( 0.020 to $0.054 \mathrm{wt} . \% \mathrm{Mg}_{\text {res }}$ ) was considered, for solidification in coated or nonceramic molds, including or excluding a sulfur source. The decrease in the residual magnesium content aggravated the degeneration of the surface graphite, five times more in mold including sulfur. The application of a mold coating strongly influenced graphite deterioration in the surface layer of castings, promoting graphite degeneration for the S-bearing coating, or conversely, limiting the surface layer thickness using desulphurization-type coatings, with Mg-bearing coatings as performance.

The main objective of the present paper is to evaluate the solidification pattern and the occurrence of graphite degeneration in the surface layer of relatively-high-silicon ductile cast iron $(3.15 \% \mathrm{Si}$, typically as 450-18 grade, ISO 1563/2011), solidified in a ceramic mold without sulfur contribution, as the influence of the mold coating (with or without $\mathrm{S}$ or O-content, and with or without supplementary addition (iron powder or carbonic material)). It is supposed that these materials could have the capacity to delay the sulfur or oxygen diffusion from the coating into the iron melt. High silicon, 450-18 ISO 1563/2011 grade, could be considered an attractive material for many applications, including heavy ductile iron castings for the windmills industry. The presence of oxygen or sulfur in the coating composition is simulated by the intentional addition of materials including these elements $\left(\mathrm{Fe}_{2} \mathrm{O}_{3}\right.$ or $\mathrm{FeS}_{2}$ ), usually used in metallurgy as sources of oxygen or sulfur due to their high capacity to supply these elements to the steel and cast iron melt.

\section{Materials and Methods}

Experimental cast iron is obtained by electrically melting, in a graphite crucible induction furnace $(10 \mathrm{~kg}, 8000 \mathrm{~Hz})$, using high-purity pig iron as the base charge material and $1565{ }^{\circ} \mathrm{C}$ temperature superheating. Table 1 includes the two main alloys selected for the double treatment, specifically for ductile cast iron production.

Table 1. Treatment alloys, wt. $\%$.

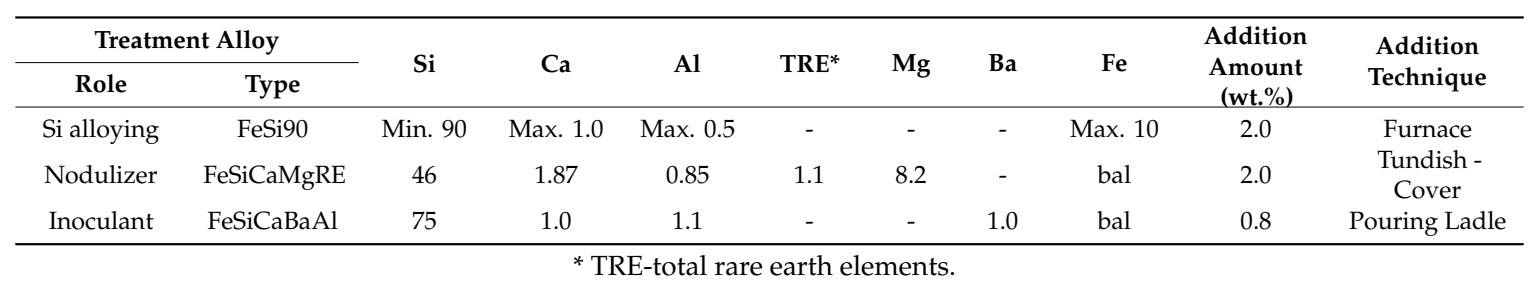

Mg-treatment (graphite nodularization) was recorded by the tundish-cover technique $\left(1500{ }^{\circ} \mathrm{C}\right.$ treatment, $8 \mathrm{~kg}$ iron melt, $2.0 \mathrm{wt} . \%$ FeSiCaMg8RE alloy addition), followed by an inoculation during the transfer of $\mathrm{Mg}$-treated iron into the pouring ladle $\left(0.8 \mathrm{wt} . \% \mathrm{FeSiCaBaAl}\right.$ alloy addition, $\left.1430{ }^{\circ} \mathrm{C}\right)$. This covered ladle method, as a tundish cover removable type, which is used in this experiment, limits the oxygen volume available during the hot metal reaction with the Mg-bearing alloy, which is not done with open ladle methods, resulting in important benefits: Reduction of smoke and flare, improved Mg-recovery, reduced temperature losses, better consistency of final $\mathrm{Mg}$. A pocket is made in the bottom of the ladle, to receive Mg-bearing FeSi, while the liquid base iron is delivered from the tundish through a calibrated hole, in a ladle with a 2:1 ratio between height and diameter.

The solidification pattern of the obtained Mg-treated and inoculated ductile cast iron is evaluated by standard thermal (cooling curve) analysis, QuiK-Cup ${ }^{\circledR}$ (Heraeus Electro-Nite International, Houthalen, Belgium) [14], which is a disposable measurement test cup that is securely attached to the contact block of the QuiK-Cup ${ }^{\circledR}$ holder. The system measures the cooling attributes of the molten iron poured into the QuiK-Cup ${ }^{\circledR}$. Various types of QuiK-Cups ${ }^{\circledR}$ are available depending on measurement type 
and iron grade. In the present work, it was used as a ceramic cup, with a $7.3 \mathrm{~mm}$ cooling modulus and $0.35 \mathrm{~kg}$ mass. This mold media is without free sulfur or oxygen for supplying to the iron melt before solidification, to affect the structure characteristics. This experimental procedure is selected as this thermal analysis system is a quick, simple, reliable, and low-cost method for shop floor control of molten iron, with a large application in the world foundry industry [14].

Different coatings are prepared for the inner surface of the ceramic cup, based on polystyrene and toluene solution ( $4 \mathrm{~g}$ polystyrene and $10 \mathrm{~mL}$ toluene): S-bearing coating $\left(0.6 \mathrm{~g} \mathrm{FeS}_{2}\right)$; O-bearing coating (0.6 $\mathrm{g} \mathrm{Fe}_{2} \mathrm{O}_{3}$ ); Fe-powder-bearing coating (1.12 $\mathrm{g}$ iron powder); carbonic-material (MC)-bearing coating (1.0 g carbonic material powder, $99 \% \mathrm{C}$ ).

After S or O-bearing coating application on the inner surface of the ceramic cup and its drying, a new Fe-powder or MC-bearing coating is applied on the first one. It is assumed that the Fe-powder or MC-powder included in the second coating will block the sulfur or oxygen diffusion from the $\mathrm{FeS}_{2}$ or $\mathrm{Fe}_{2} \mathrm{O}_{3}$-bearing coating into the iron melt, before solidification.

The experiments could be grouped in the following variants: (a) Uncoated mold, without oxygen or sulfur available to diffuse into the iron melt, as reference variant; (b) coated mold, including oxygen $\left(\mathrm{Fe}_{2} \mathrm{O}_{3}\right.$-bearing coating) or sulfur $\left(\mathrm{FeS}_{2}\right.$-bearing coating), as potential sources of these active elements to react with iron melt, before solidification, at least in the superficial layer of casting; (c) supplementary addition of other substances (carbonic material-MC or iron powder-Fe) on the previous $\mathrm{Fe}_{2} \mathrm{O}_{3}-\mathrm{or}$ $\mathrm{FeS}_{2}$-bearing coatings, as potential blockage of oxygen or sulfur diffusion into the iron melt.

For a structure analysis, in the surface layer and casting body, samples obtained in the thermal analysis ceramic cup are used (Figure 1a). The structure is analyzed in the as-cast state, without etching (graphite analysis) and after Nital etching (metal matrix analysis).

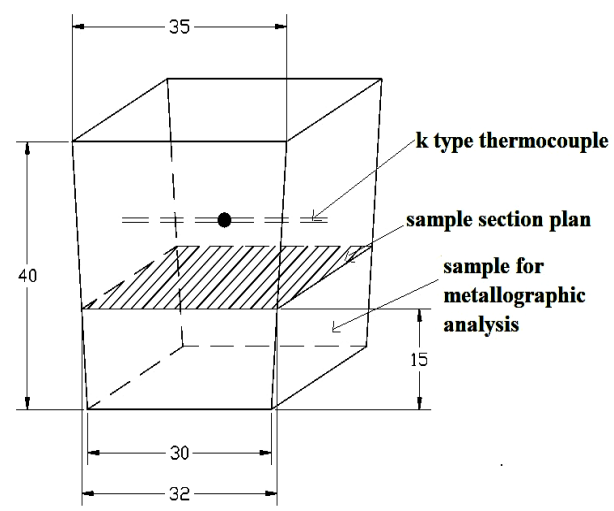

(a)

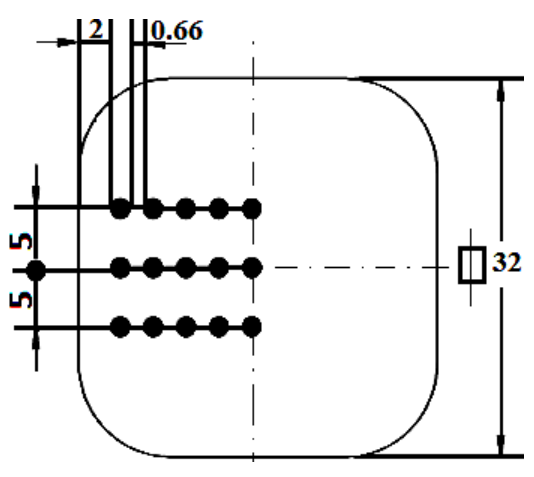

(b)
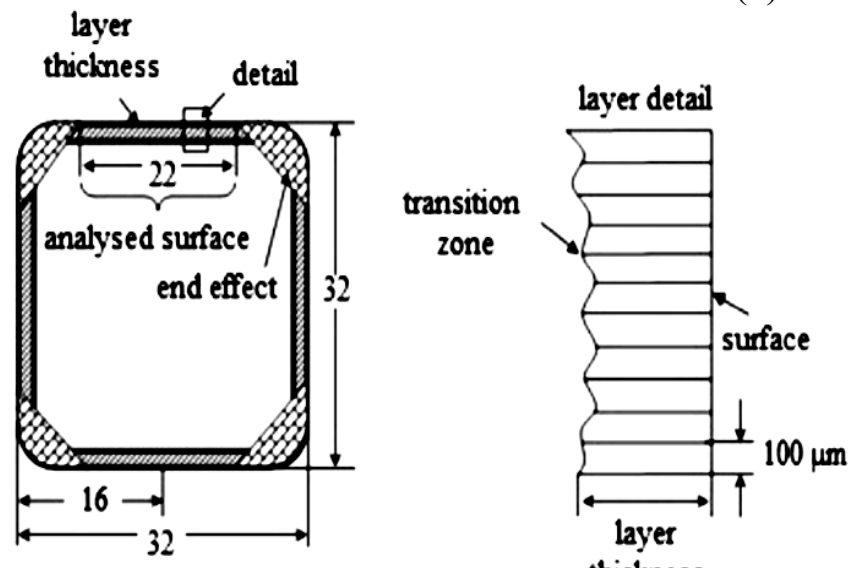

(c)

Figure 1. Metallographic sample drawn (a), analysis points on the sample section $(\mathbf{b})$ and surface layer thickness (c) evaluation [15]. 
The occurrence of the surface layer (casting skin) as position and thickness is extremely variable, depending on a lot of influencing factors. For this reason, it is not recommended to consider only one evaluated point as representative of the results in specific solidification conditions. Consequently, only a large number of measurements could offer an image of casting skin formation, as their average value. It is also known that as the cast structure is relatively un-homogeneous also in the casting body, an average value of structure characteristics is more representative for each considered parameter. The average values of measurements are plotted in the graphs, and typical structures, selected as representative for each tested variant, are considered.

To evaluate the structure characteristics in the casting body, three analysis directions are considered, each one with 5 analysis points ( 15 analyses in total), placed in the same positions, outside the surface layer and casting center, to avoid their influence (Figure 1b). The end effect is avoided, so a $22 \mathrm{~mm}$ analysis length is used on each side. For each side, the layer thickness is measured in points $100 \mu \mathrm{m}$ apart (Figure 1c). The final result is expressed as the average of all measurements (220 measurements on each side, 880 in total) [15]. A metallographic microscope is used for the measurements of the surface layer, at a magnification of 100:1.

\section{Results and Discussion}

\subsection{Chemical Composition}

According to Table 2 data, the final cast iron, after Mg-treatment and ladle inoculation, occupies a hyper-eutectic position, as carbon equivalent $\mathrm{CE}=4.6 \%$, at normal contents of the elements usually present in the base chemical composition, including residual magnesium $\left(0.049 \% \mathrm{Mg}_{\text {res }}\right)$. According to the size characteristics of the test samples, graphite flotation phenomena are not registered. High-purity charge materials lead to limited content of minor elements, typically as (wt. $\%): 0.08 \mathrm{Cr}, 0.05 \mathrm{Mo}, 0.072 \mathrm{Ni}$, $0.002 \mathrm{Al}, 0.02 \mathrm{Cu}, 0.016 \mathrm{~V}, 0.004 \mathrm{~W}$, less than $0.002 \mathrm{~Pb}$ and $\mathrm{Bi}$, less than $0.005 \mathrm{Sn}, \mathrm{Sb}, \mathrm{As}, \mathrm{Sb}$, Ti. Consequently, the experimental ductile cast irons are characterized by low antinodularizing potential $(K<0.8)$ and low sensitivity of pearlite formation $(\mathrm{Px}<1)$, according to Thielemann equations [16].

Table 2. Chemical composition of Mg-treated and inoculated cast iron.

\begin{tabular}{|c|c|c|c|c|c|c|c|c|}
\hline \multicolumn{6}{|c|}{ Chemical Composition, wt.\% } & \multirow{3}{*}{$\begin{array}{c}\begin{array}{c}\text { Carbon Equivalent * } \\
\%\end{array} \\
\mathrm{CE} \\
4.6\end{array}$} & \multirow{3}{*}{$\begin{array}{c}\begin{array}{c}\text { Antinodulizing } \\
\text { Factor }\end{array} \\
\mathrm{K} \\
0.72\end{array}$} & \multirow{2}{*}{$\begin{array}{c}\text { Pearlitic } \\
\text { Factor }^{* * *}\end{array}$} \\
\hline $\mathrm{C}$ & $\mathrm{Si}$ & Mn & $\mathrm{P}$ & $S$ & $\mathrm{Mg}$ & & & \\
\hline 3.65 & 3.15 & 0.1 & 0.013 & 0.004 & 0.049 & & & -0.22 \\
\hline
\end{tabular}

\subsection{Thermal (Cooling Curves) Analysis}

Figure 2 [17] illustrates the representative events on the cooling curve, as temperatures and undercooling degrees, respectively, for applied standard thermal (cooling curve) analysis for commercial ductile cast iron, solidified in nonequilibrium conditions, typically for industrial metal castings production. 


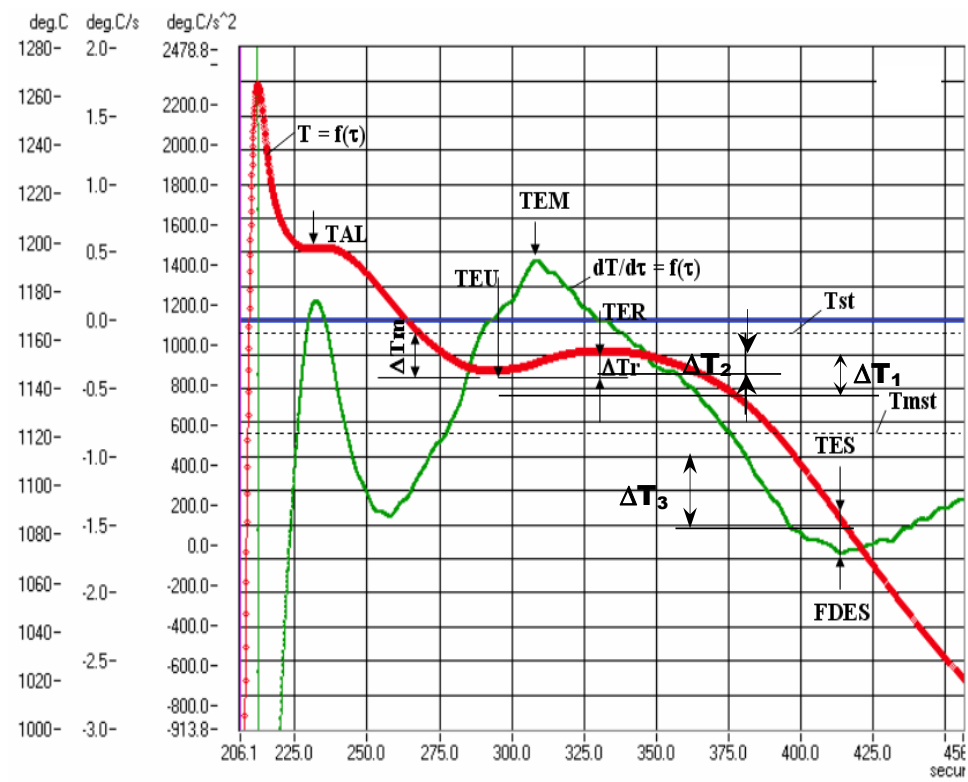

Time, $\tau$, sec

Figure 2. Representative solidification temperatures and undercooling degrees $(\Delta \mathrm{T})$ compared to equilibrium temperature in stable (graphitic) $\left(\mathrm{T}_{\mathrm{st}}\right)$ and metastable (carbidic) $\left(\mathrm{T}_{\mathrm{mst}}\right)$ systems of ductile cast iron [17].

Equilibrium temperatures $\mathrm{T}_{\mathrm{st}}$ and $\mathrm{T}_{\mathrm{mst}}$ are influenced by many elements, present in the chemical composition, as increasing or decreasing by different powers, usually with silicon as the most influencing element. Consequently, these temperatures are calculated depending on the silicon content, according to Equations (1) and (2) [18,19]:

$$
\begin{gathered}
\mathrm{T}_{\mathrm{st}}=1153+6.7(\text { wt. } \% \mathrm{Si})\left({ }^{\circ} \mathrm{C}\right), \\
\mathrm{T}_{\mathrm{mst}}=1147-12(\text { wt. } \% \mathrm{Si})\left({ }^{\circ} \mathrm{C}\right),
\end{gathered}
$$

TEU represents the lowest temperature of the eutectic reaction, attended below the equilibrium temperature in the stable (graphitic) system $\mathrm{T}_{\mathrm{st}}$, at a difference defined by the maximum eutectic undercooling degree $\Delta \mathrm{Tm}=\mathrm{T}_{\mathrm{st}}-\mathrm{TEU}$. This temperature could be above or below the equilibrium temperature in a metastable system, $\mathrm{T}_{\mathrm{mst}}$.

The eutectic reaction will continue after TEU time with heat generation (austenite and eutectic formation), causing the temperature to rise until TER (the highest eutectic reaction temperature) is reached. The TER $-\mathrm{TEU}=\Delta \operatorname{Tr}$ difference is defined as eutectic recalescence. Solidification will continue with decreasing temperature. The solidification of the last part of the liquid iron is marked by TES (temperature of the end of solidification), usually determined by the help of the first derivative of the cooling curve (corresponding to the lowest level of the first derivative, the first derivative at the end of solidification (FDES) position).

TEU and TER parameters are important to express the sensitivity of cast iron to graphite or carbides formation and graphite morphologies characteristics, while the TES value is important to evaluate the sensitivity to inter-eutectic cell carbides and micro-shrinkage formation in the last solidified iron melt, at the end of solidification. Commercial/industrial iron castings (with more than 30 elements in chemical composition) solidify in nonequilibrium conditions (solidification cooling rate many times higher than in equilibrium conditions), which affect the quality and the soundness of castings, especially as free carbides and micro-shrinkage formation in the inter-eutectic cell areas, at the end of solidification. Several elements segregate to the rest melt and lower TES. A low TES increases the risk for inverse chill, i.e., formation of primary carbides at the last phases to solidify. In this respect, the TES 
parameter is very important: Lower TES values, or a more negative $\Delta \mathrm{T}_{3}$ undercooling parameter, means high sensitivity to form these defects. More information on the evaluation parameters at the end of solidification, such as TES, FDES-the first derivative at the end of solidification (the lowest pick on the first derivative, which corresponds to TES on the cooling curve), or graphitization factors GRF2 (as angle of the first derivative curve at FDES) are offered in papers $[18,19]$. For example, high GRF2 indicates an increased risk for micro-shrinkages and detrimental undercooled graphite shapes (type $\mathrm{D}$ and E) in grey cast iron.

At the beginning of the thermal analysis application in cast iron solidification control in the foundry industry, Tst $-\mathrm{TEU}=\Delta \mathrm{Tm}$ (as the maximum undercooling referring to stable equilibrium temperature) and TER-TEU (as recalescence) are used. They are also used currently, in solidification simulation systems. However, over time, it has been observed that the referring of the cooling curve events to the metastable (carbidic) temperature $\left(\mathrm{T}_{\mathrm{mst}}\right)$ offered direct and clearer information. The positions of the representative temperatures TEU, TER, and TES compared to the eutectic equilibrium temperature in the metastable (carbidic) solidification system $\left(\mathrm{T}_{\mathrm{mst}}\right.$ ) are expressed by specific undercooling degrees (Figure 2):

$$
\begin{aligned}
& \Delta \mathrm{T}_{1}=\mathrm{TEU}-\mathrm{T}_{\mathrm{mst}}, \\
& \Delta \mathrm{T}_{2}=\mathrm{TER}-\mathrm{T}_{\mathrm{mst}}, \\
& \Delta \mathrm{T}_{3}=\mathrm{TES}-\mathrm{T}_{\mathrm{mst}},
\end{aligned}
$$

The values of these undercooling degrees allow us to evaluate the structure characteristics and the quality of the iron castings, such as:

- $\quad \Delta \mathrm{T}_{1}<0$ and $\Delta \mathrm{T}_{2}<0$ : Only carbides, not graphite formation (white cast iron);

- $\Delta \mathrm{T}_{1}<0$ and $\Delta \mathrm{T}_{2}>0$ : Carbides at the beginning and graphite at the end of eutectic reaction (mottled cast iron);

- $\quad \Delta \mathrm{T}_{1}>0$ and $\Delta \mathrm{T}_{2}>0$ : Only graphite formation (graphitic cast iron);

- $\Delta \mathrm{T}_{3}<0$ usually, as TES $<\mathrm{T}_{\mathrm{mst}}$ for most of the commercial cast irons, solidified in industrial conditions (the lower the TES (more negative), the higher the incidence of inter-cells events formation).

Figure 3 shows the aspect of typical solidification cooling curves obtained in the present experimental program, with representative temperatures TEU, TER, and TES included in Figure 4.

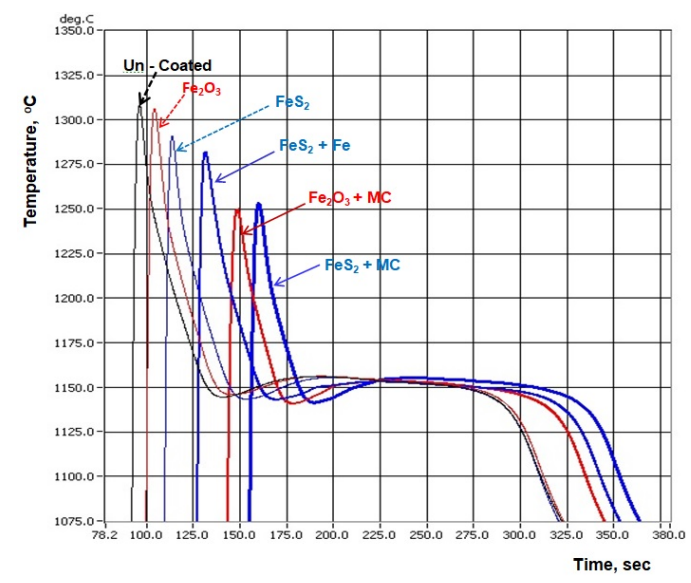

Figure 3. Solidification cooling curves of tested ductile cast irons, for uncoated and different innercoated ceramic cups. 


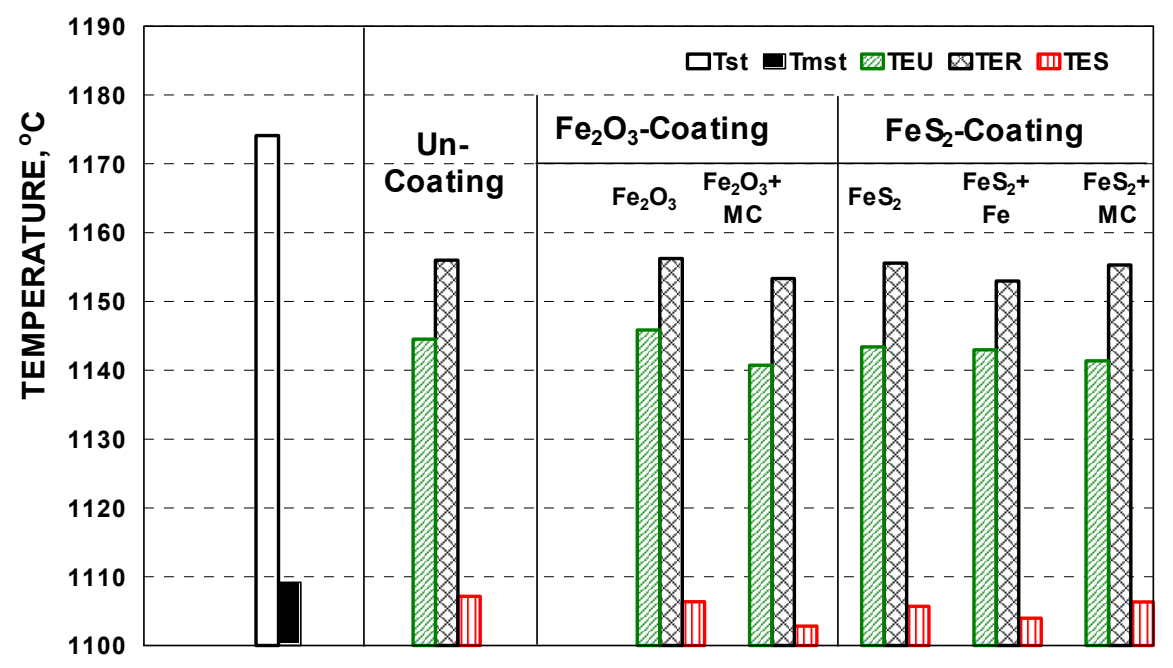

Figure 4. The lowest (TEU) and the highest (TER) temperatures during eutectic reaction and at the end of solidification (TES) for uncoated and different inner coated ceramic cups, compared to stable $\left(\mathrm{T}_{\mathrm{st}}\right)$ and metastable $\left(\mathrm{T}_{\mathrm{mst}}\right)$ equilibrium eutectic temperatures.

It is supposed that in the present experimental program, the solidification parameters of inoculated ductile iron, identified by thermal (cooling curve) analysis, could be influenced by two important factors. For the same used mold media (ceramic cup), with defined thermal-physical properties (Table 3) [20], different coatings, applied on the inner mold surface, could be influencing factors on the solidification cooling rate, and also, consequently, the cooling curves parameters, due to their different thermal-physical properties (Table 3). Higher thermal diffusivity could be a premise for higher solidification cooling rates.

Table 3. Typical thermo-physical properties of used materials.

\begin{tabular}{ccccc}
\hline Material & $\begin{array}{c}\text { Thermal Diffusivity } \\
\left(\mathbf{W ~ s}^{\mathbf{1} / \mathbf{2}} / \mathbf{m}^{\mathbf{2}} \mathbf{K}\right)\end{array}$ & $\begin{array}{c}\text { Specific Heat } \\
(\mathbf{J} / \mathbf{k g ~ K})\end{array}$ & $\begin{array}{c}\text { Thermal Conductivity } \\
\mathbf{( W / m ~ K )}\end{array}$ & $\begin{array}{c}\text { Density } \\
\left(\mathbf{k g} / \mathbf{m}^{\mathbf{3}}\right)\end{array}$ \\
\hline Ceramic cup & 1487 & 1280 & 1.08 & 1600 \\
S-bearing coating & 3585 & 547 & 5 & 4700 \\
O-bearing coating & 2044 & 650 & 1.26 & 5100 \\
Fe-powder-bearing coating & 16,221 & 450 & 74.4 & 7870 \\
Carbonic-material-bearing coating & 14,410 & 710 & 129 & 2267 \\
\hline
\end{tabular}

On the other hand, the presence of active materials in the coating composition, such as $\mathrm{Fe}_{2} \mathrm{O}_{3}$, $\mathrm{FeS}_{2}$, carbonic material powder (MC), or iron powder ( $\mathrm{Fe}$ ) could influence the solidification pattern, according to their capacity to diffuse into the iron melt themself, or depending on their capacity to block the diffusion of other substances.

It is expected that oxygen and sulfur diffused into the iron melt will have a complex contribution on the graphite phase: As active elements in graphite formation, by their contribution in the three-stage formation of graphite nucleation sites (sulfides-silicates-graphite) [21], favoring the solidification at lower undercooling (usually as higher TEU, TER, TES); but also in degeneration of nodular/spheroidal graphite, as these elements will consume part of the nodulizing elements, decreasing them under a critical level.

Consequently, it is expected that the tested coating variants could have a complex action, contributing to the increase in the solidification cooling rate, by their higher thermal diffusivity, but at the same time, to the decrease in the solidification cooling rate, by their contribution in graphite formation (as a result of supplied $\mathrm{O}$ and $\mathrm{S}$ ), without the necessity of higher undercooling.

The lowest eutectic temperature (TEU), registered in the first part of the eutectic reaction, is affected by mold coating application, but in different ways and power. Generally, the increase in 
TEU level is a positive effect of potential influencing factors, at least for decreasing the sensitivity to free carbide formation. The $\mathrm{Fe}_{2} \mathrm{O}_{3}$-bearing coating increased (1145.87 versus $1144.53^{\circ} \mathrm{C}$ ) and the $\mathrm{FeS}_{2}$-bearing coating decreased $\left(1143.40\right.$ versus $\left.1144.53^{\circ} \mathrm{C}\right)$ the TEU level, compared to uncoated mold solidification. MC-carbonic material supplementary addition led to the visible decrease in TEU values for both $\mathrm{Fe}_{2} \mathrm{O}_{3}\left(1140.73\right.$ versus $1145.87^{\circ} \mathrm{C}$ ) and $\mathrm{FeS}_{2}$-bearing coating $\left(1141.39\right.$ versus $1143.40^{\circ} \mathrm{C}$ ) applications, according to its capacity to increase the thermal properties of these coatings and cooling rate, respectively; iron powder addition also decreased the TEU level, for the same reason.

The highest eutectic temperature, as a result of the eutectic recalescence, TER, is only a little bit increased by the oxygen-bearing coating (1156.22 versus $\left.1156.01{ }^{\circ} \mathrm{C}\right)$, but it is not affected by the sulfur-bearing coating. The carbonic material visibly decreases the recalescence temperature for the $\mathrm{Fe}_{2} \mathrm{O}_{3}$ coating $\left(1153.34\right.$ versus $1156.22{ }^{\circ} \mathrm{C}$ ), but only at a limited level for the $\mathrm{FeS}_{2}$-bearing coating. Iron powder visibly decreases the TER level for $\mathrm{FeS}_{2}$-bearing coating application (1152.96 versus $\left.1155.59^{\circ} \mathrm{C}\right)$.

The temperature at the end of solidification TES is at a lower level for all the tested mold coating variants, compared to the uncoated mold solidification. It decreases from $1107.17^{\circ} \mathrm{C}$ for the uncoated to $1106.39^{\circ} \mathrm{C}$ for the $\mathrm{Fe}_{2} \mathrm{O}_{3}$ coating and up to $1105.7^{\circ} \mathrm{C}$ for the $\mathrm{FeS}_{2}$ coating. Supplementary carbonic material or iron powder addition decreases the temperature much more at the end of solidification. At the end of solidification, when the casting is solidified in the outer region, the coating does not act anymore as a supplier of oxygen and sulfur, beneficial for graphite formation at lower undercooling, but it will contribute to the increase in the casting cooling rate, by its higher thermal diffusivity, resulting in a decrease in the TES parameter.

If the representative temperatures TEU, TER, and TES are referred to the equilibrium eutectic temperature in the metastable (carbidic) solidification system, $\mathrm{T}_{\mathrm{mst}}, \Delta \mathrm{T}_{1}, \Delta \mathrm{T}_{2}$, and $\Delta \mathrm{T}_{3}$ solidification undercooling degrees (Equations (3)-(5)) will result (Figure 5).

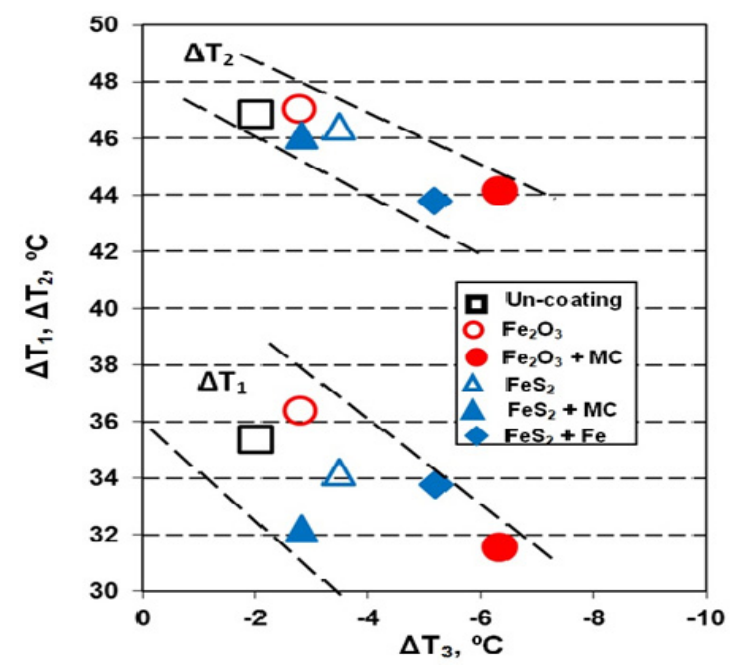

Figure 5. Relationship between the solidification undercooling at the lowest $\left(\Delta \mathrm{T}_{1}\right)$ and the highest $\left(\Delta \mathrm{T}_{2}\right)$ eutectic reaction and at the end of solidification $\left(\Delta \mathrm{T}_{3}\right)$ compared to metastable (carbidic) eutectic temperature $\left(\mathrm{T}_{\mathrm{mst}}\right)$ for uncoated and different inner-coated ceramic cups.

Positive values for both $\Delta \mathrm{T}_{1}$ and $\Delta \mathrm{T}_{2}$ sustain graphitic solidification of the experimental double-treated (Mg-treatment + inoculation) cast iron, at relatively higher silicon contents (more than $3 \% \mathrm{Si})$. The negative values for $\Delta \mathrm{T}_{3}\left(-2, \ldots,-8{ }^{\circ} \mathrm{C}\right)$ show that the temperature of the end of solidification (TES) remains below, but closer than, $\mathrm{T}_{\mathrm{mst}}$. Figure 5 illustrates a good relationship between the undercooling degree at the lowest eutectic temperature TEU, in the first part of the eutectic reaction $\left(\Delta \mathrm{T}_{1}\right)$ and at the end of solidification $\left(\Delta \mathrm{T}_{3}\right)$; and between the undercooling degree at the highest (recalescence) temperature TER $\left(\Delta \mathrm{T}_{2}\right)$ and at the end of solidification $\Delta \mathrm{T}_{3}$, respectively. If the applied coatings do not change these expected relationships, it is found that at the beginning of eutectic 
reaction, the relationship $\left(\Delta \mathrm{T}_{1}-\Delta \mathrm{T}_{3}\right)$ is stronger than at the maximum recalescence rate $\left(\Delta \mathrm{T}_{2}-\Delta \mathrm{T}_{3}\right)$, but with results at a larger distribution. On the other hand, it is visible that a coating variant could have different positions referring to $\Delta \mathrm{T}_{1}$ and $\Delta \mathrm{T}_{2}$, such as $\mathrm{FeS}_{2}$-included coatings.

Mold coating status has an important effect on the undercooling degree levels and relationship. Solidification in the uncoated mold is characterized by a high level of $\Delta \mathrm{T}_{1}, \Delta \mathrm{T}_{2}$, and $\Delta \mathrm{T}_{3}$ (less negative) parameters. The lowest level of these parameters is generally obtained by carbonic material or iron powder addition to the oxygen or sulfur-bearing coatings. Limited effects and, in any case, apparent contradictions reported for these coatings as their influence on the cooling curves morphology are evidence that this is not the most important contribution, from the two possible effects, mentioned before: Influence on the solidification pattern or their contribution in graphite degeneration.

\subsection{Structure Analysis}

\subsubsection{Casting Body}

The microstructures included in Figure 6 show the effect of the coating of the ceramic mold on the structure of the obtained body of ceramic cup casting (see Figure 1b), in unetched (graphite phase) and Nital-etched (metal matrix) conditions. The graphite characteristics are evaluated with Automatic Image Analysis (OMNIMET ENTERPRISE and analySIS ${ }^{\circledR}$ FIVE Digital Imaging Solutions software). For graphite nodularity $(\mathrm{N})$, this software uses Equation (6):

$$
\mathrm{N}=\left[\left(\sum \mathrm{A}_{\mathrm{NG}}+1 / 2 \sum \mathrm{A}_{\mathrm{IG}} / \sum \mathrm{A}_{\mathrm{tot}}\right] \cdot 100\right.
$$

where:

$\mathrm{A}_{\mathrm{NG}}$ is the area of particles classified as nodules (RSF $\left.=0.625-1.0\right)$;

$\mathrm{A}_{\mathrm{IG}}$-area of particles classified as intermediates ( $\mathrm{RSF}=0.525-0.625$ );

$\mathrm{A}_{\text {tot }}$-area of all graphite particles;

$\mathrm{RSF}=4 \mathrm{~A} /\left(\pi \mathrm{lm}^{2}\right)$;

A-area of the graphite particle in question;

$\mathrm{lm}$-maximum axis length of the graphite particle in question (maximum distance between two points on the graphite particle perimeter).

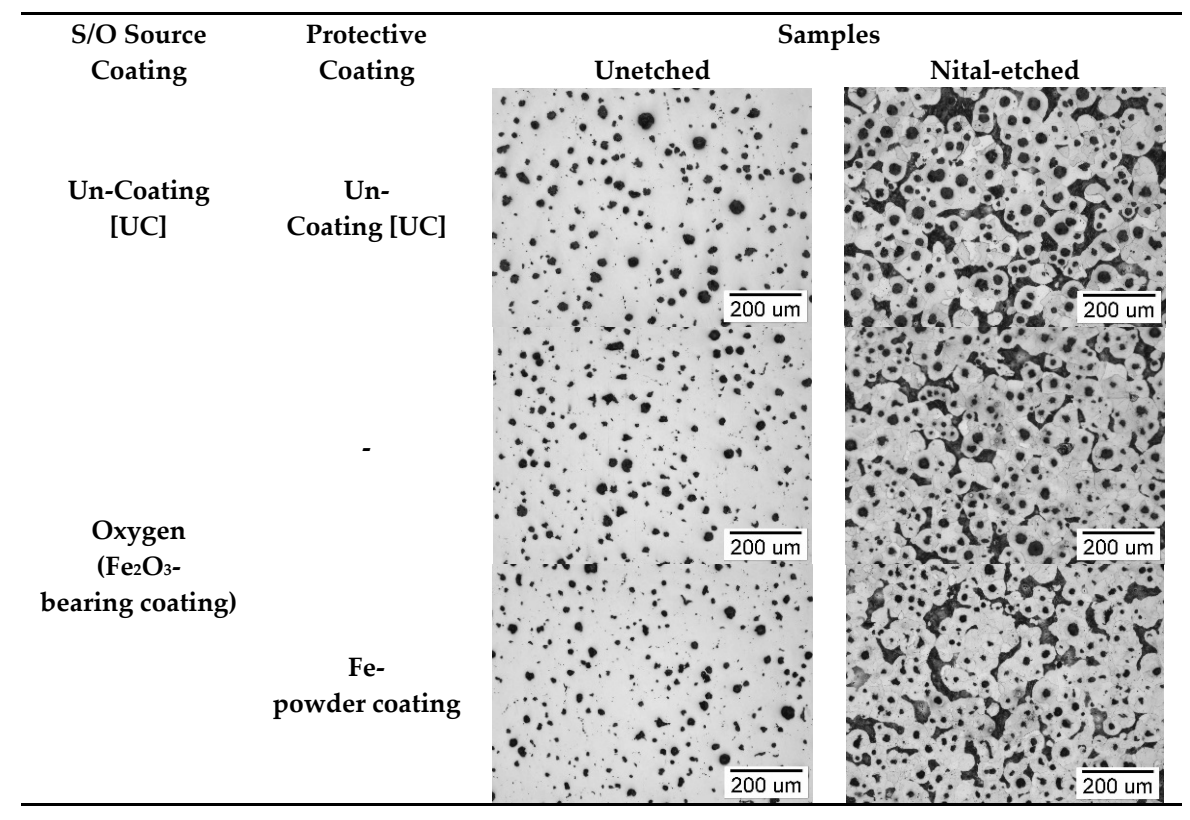

Figure 6. Cont. 


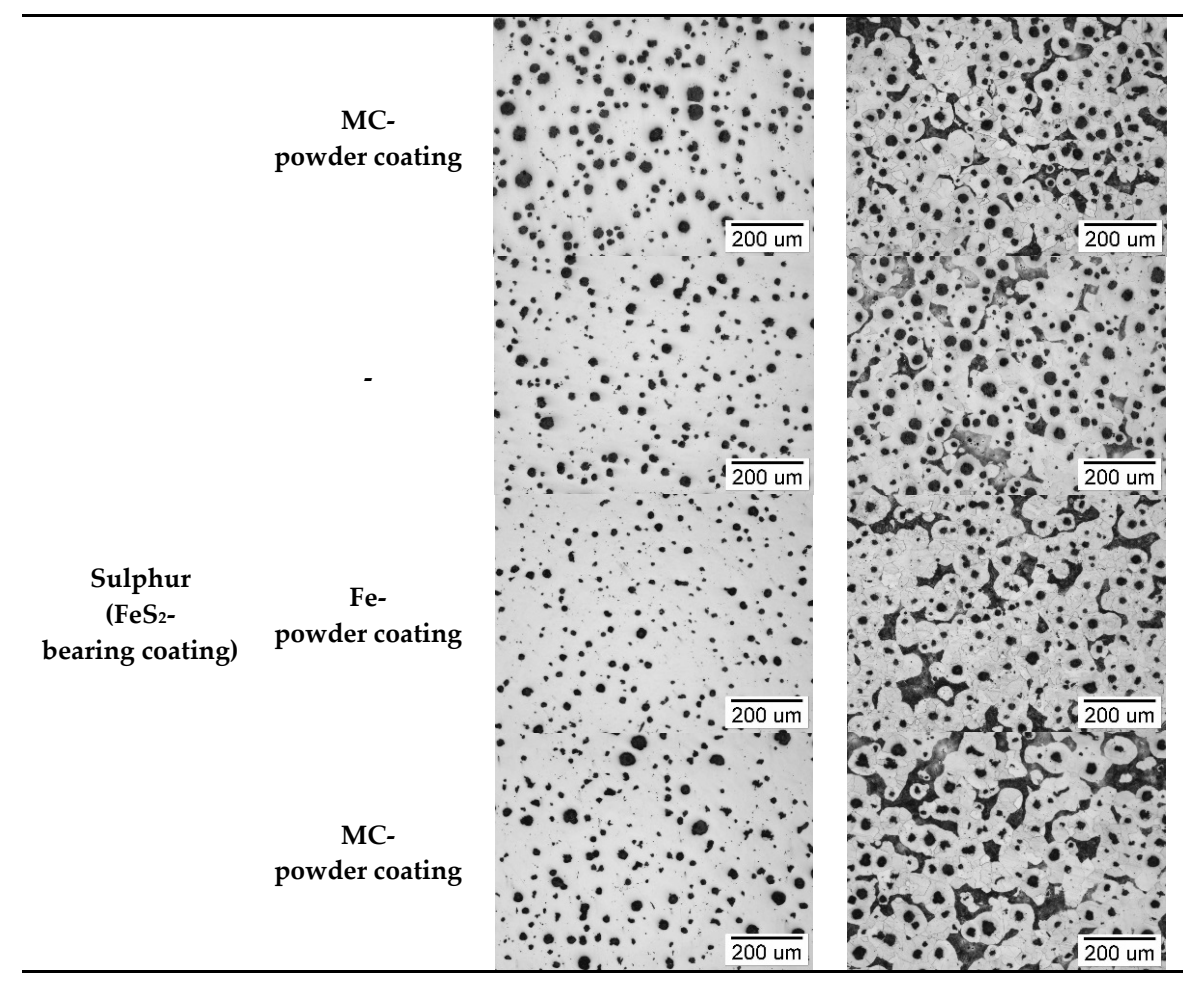

Figure 6. Typical structure characteristics in the casting body (unetched and Nital-etched).

In all the cases, a good nodular graphite cast iron is obtained, with a more than $85 \%$ graphite nodularity level in the uncoated mold casting. The $\mathrm{Fe}_{2} \mathrm{O}_{3}$ and $\mathrm{FeS}_{2}$-bearing coating has a limited effect on the graphite nodularity inside the casting, by reducing the nodularity up to the $82 \%-83 \%$ level. Application of the carbonic-material- or iron-powder-bearing supplementary coating on the previous oxygen or sulfur-bearing coating acted in a positive manner, as graphite nodularity increased up to $83.5 \%-84 \%$, but in a different association formula. Better results are obtained by carbonic material addition on the $\mathrm{Fe}_{2} \mathrm{O}_{3}$-bearing coating and iron powder on the $\mathrm{FeS}_{2}$-bearing coating, respectively. The presence of oxygen or sulfur in the mold coating appears to favor the formation of lower-sized graphite nodules, while the carbonic material included in the mold coating leads to an increased amount of higher-sized graphite nodules in the casting body structure.

Metal matrix is mainly ferritic type, at less than $15 \%$ pearlite, without the presence of free carbides, according to the lower pearlitic potential of the chemical composition (high content of silicon and low content of manganese and minor elements). A higher ferrite amount ( $>90 \%$ ferrite) accompanies the lower size and higher graphite particles count favored by the oxygen or sulfur-bearing mold coating. A lower graphite nodularity level, which means a higher incidence of non-spheroidal graphite particles, resulting from the action of mold coating including oxygen or sulfur, also contributes to ferrite formation.

\subsubsection{Surface Layer of Castings}

Figure 7 shows the structure of the experimental ductile cast iron in the surface layer of castings, in all test variants, as effects of mold coatings application. Figure 8 illustrates the larger casting surface structure, for S-bearing coating application. 


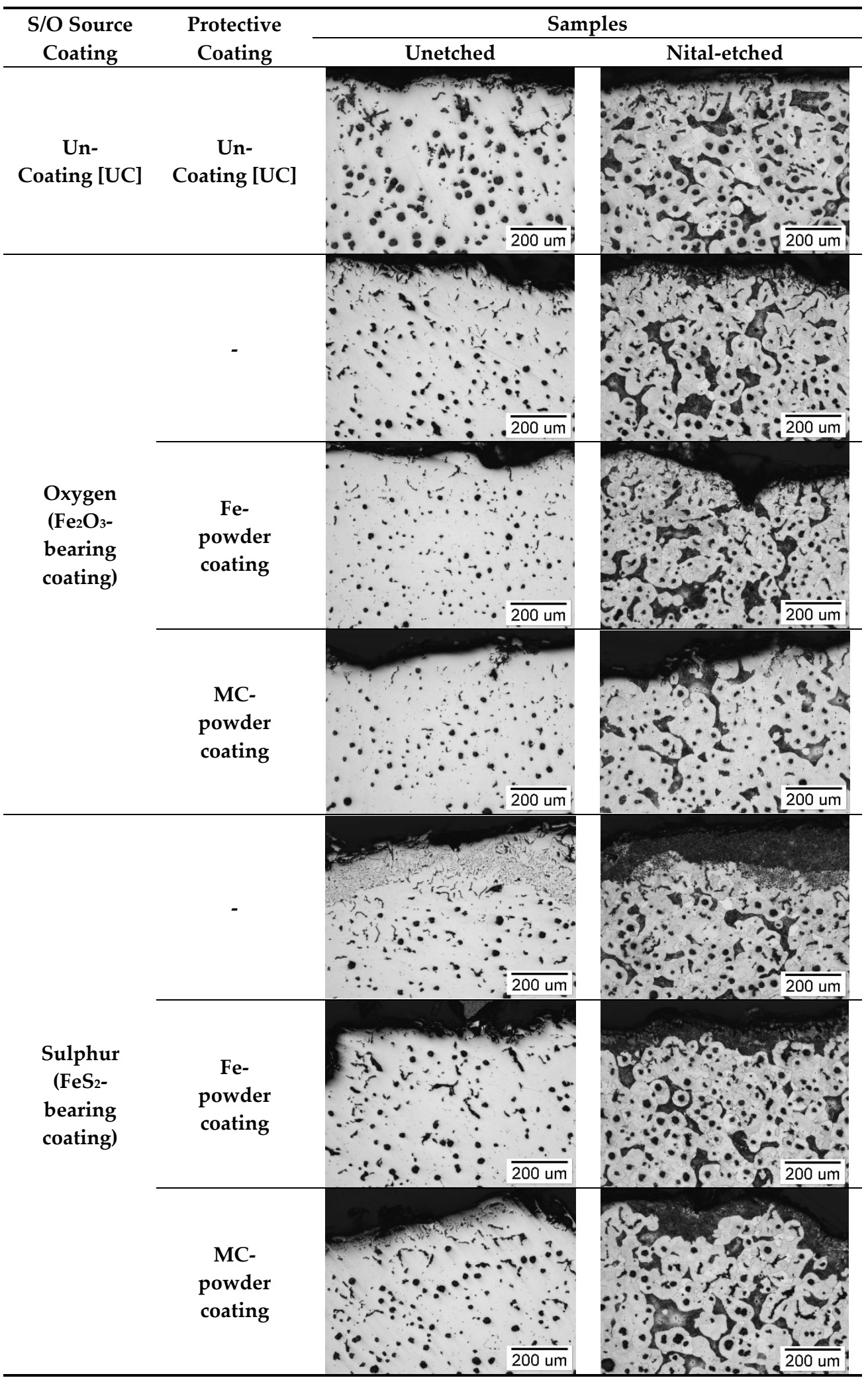

Figure 7. Typical structure of the Mg-treated and inoculated cast iron in the casting surface layer. 


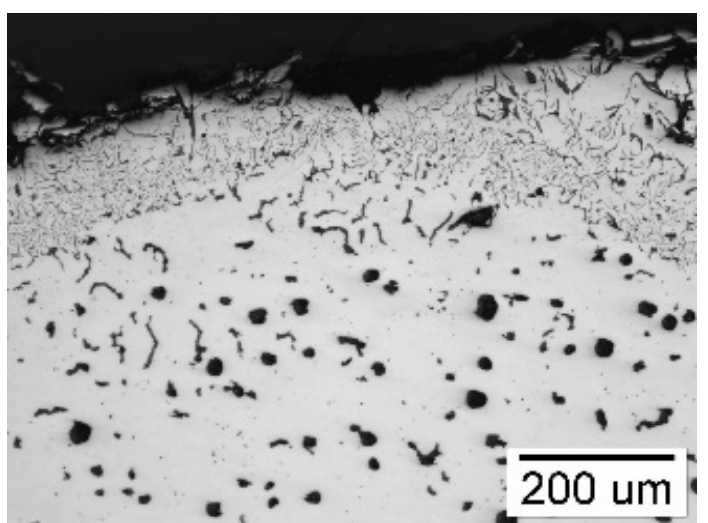

(a)

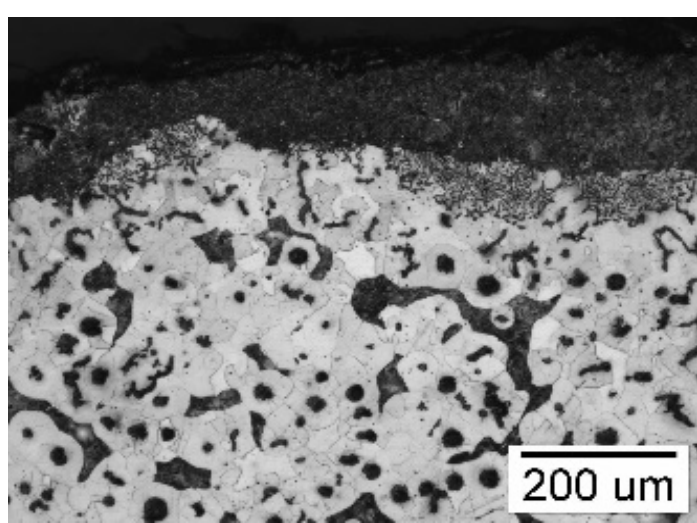

(b)

Figure 8. Unetched (a) and Nital-etched (b) casting surface structure, at larger pictures (S-bearing coating).

Typically, for the Mg-treated iron castings, there is the presence of a surface layer (casting skin) with an altered structure as the graphite phase morphology. This means a decreased graphite phase compactness degree, with a transition between nodular (spheroidal) graphite in the casting body through mixture morphologies (nodular, compacted, lamellar graphite) at the casting surface. The presence of the casting skin is visible in both unetched and Nital etching samples conditions, but at different levels depending on the mold coating status (Figure 9). In the unetched structure, only the graphite phase is considered. In this case, the degenerated graphite layer thickness is considered up to the nodular graphite morphology appearance, without other visible graphite morphologies, such as lamellar and compacted graphite.

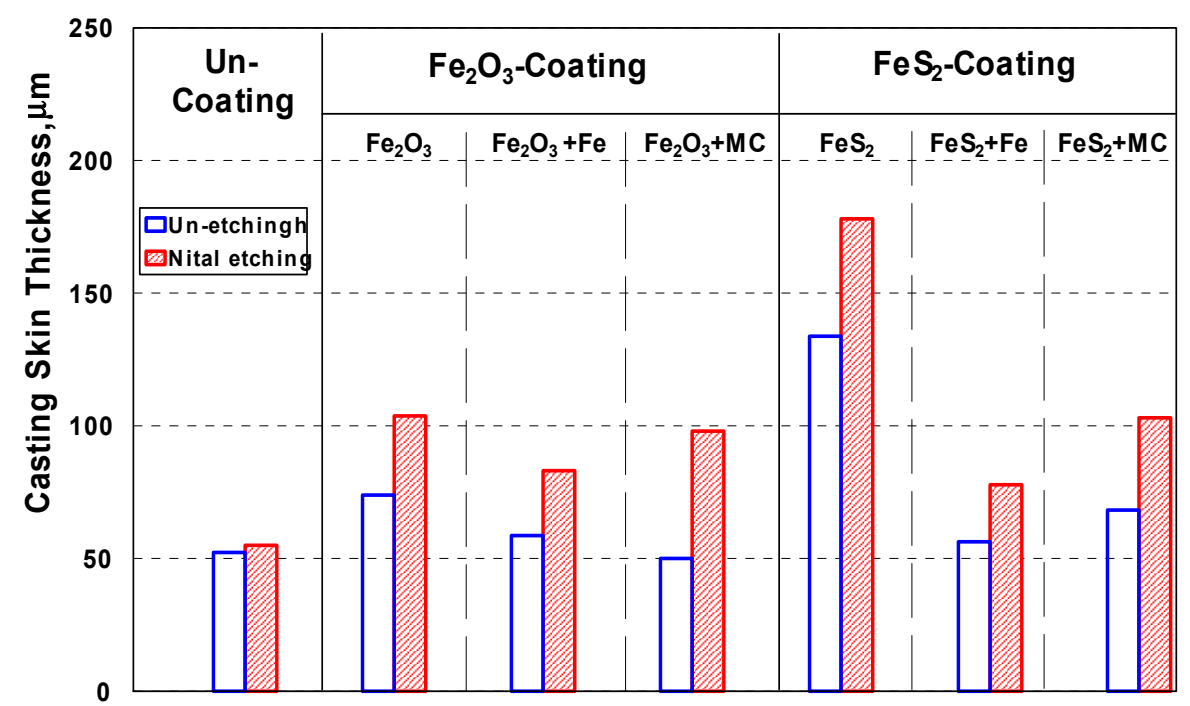

Figure 9. Average graphite degenerated surface layer (casting skin) thickness of experimented ductile irons.

In the Nital etching structure, not only graphite but also metal matrix is considered. There exists a difference between the surface layer and casting body not only as graphite morphology but also as metal matrix make-up. In the casting surface layer, formed lamellar graphite promotes pearlite while very fine lamellar graphite and compacted graphite promote ferrite, resulting in a layer not only with a mixture of graphite morphologies but also with a mixture of metal matrix constituents. The thickness of this surface layer is considered in the Nital etching conditions.

Despite this, in the present experiments, the used ceramic mold is not able to supply active agents for nodularizing elements consumption into the iron melt, and a surface layer at different graphite 
morphologies compared to the casting body is present, but at a large range of thicknesses, from 50 up to $200 \mu \mathrm{m}$.

The lowest thickness of the surface layer (skin) is obtained without mold coating, at an average size at $52.3 \mu \mathrm{m}$ for unetched (graphite phase evaluation), and $54.97 \mu \mathrm{m}$ for Nital etching (metal matrix evaluation). A higher level of skin thickness as metal matrix evaluation compared to the graphite phase evaluation is present in all of the experimented variants. This situation is confirmed also in other research works $[22,23]$. Both oxygen or sulfur included in the mold coating increase the casting skin thickness, but at different powers: Up to $50 \%$ by oxygen and 2.5-3.3 times for sulfur action, respectively, despite the fact that in the casting body, the graphite nodularity decreases only from $85 \%$ up to $82 \%-83 \%$. Supplementary iron powder addition, supposed to block oxygen or sulfur diffusion from the mold coating into the iron melt, is efficient, as the skin thickness decreases from 73.93 to $58.68 \mu \mathrm{m}$ for the oxygen-bearing coating and especially from 133.75 to $56.34 \mu \mathrm{m}$ for sulfur presence in the mold coating, for unetched samples evaluation. For metal matrix evaluation (Nital etching samples), a decrease from 103.73 to $83.06 \mu \mathrm{m}$ is found for the oxygen-bearing coating and from 178 to $77.81 \mu \mathrm{m}$ for the sulfur-bearing coating. Similarly, positive effects are also obtained by carbonic material addition.

Some visible structure characteristics could also be observed for the casting body just below the surface layer (skin) for the test variants. Larger-sized nodules and degenerated graphite morphologies (like spiky-graphite) could be noted for the uncoated mold, and small-sized nodules for coated molds. The ferritic structure characterizes all the analyzed structures.

Figure 10 summarizes the obtained results, as the effects of the mold coating on the solidification parameters, expressed by the undercooling degree at the lowest eutectic temperature, in the first part of solidification $\left(\Delta \mathrm{T}_{1}\right)$ and at the end of solidification $\left(\Delta \mathrm{T}_{3}\right)$ on the one hand, and the casting skin thickness, resulting from the influence of the tested mold coatings, on the other hand.

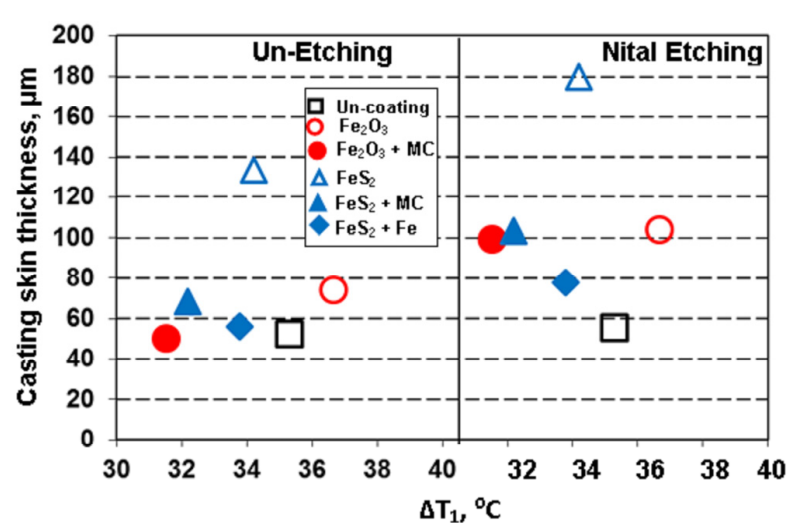

(a)

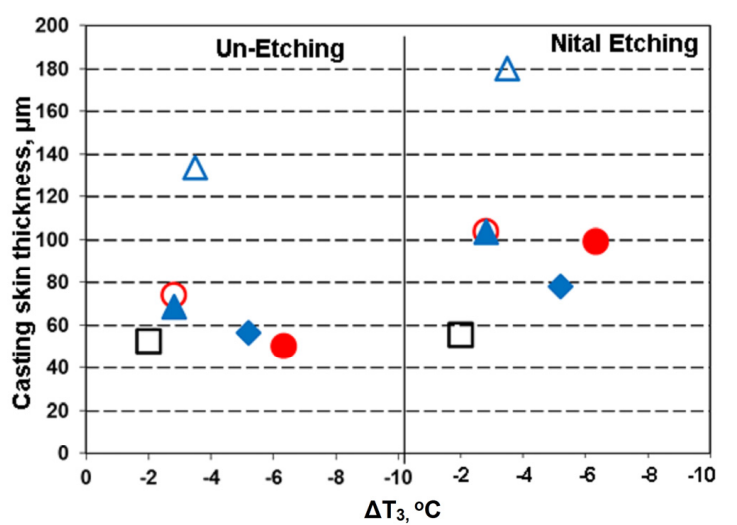

(b)

Figure 10. Casting skin thickness for uncoated and different inner-coated ceramic cups, in unetched (graphite) and Nital etching (metal matrix) evaluation conditions (a) $\Delta \mathrm{T}_{1} ;$ (b) $\Delta \mathrm{T}_{3}$ relationship.

Despite this, the applied coatings influence the solidification pattern not only by their thermal-physical properties, influencing the solidification cooling rate in this way, but also as possible sources for active substances, supposed to be able to diffuse into the iron melt, before solidification; to affect structure formation, the casting skin formation appears to be attributed mainly to the second influencing factor.

The highest thickness of the graphite surface degeneration layer (casting skin) resulted from the presence of sulfur in the mold coating, despite the fact that the casting solidification is characterized by a medium undercooling in the first part of the eutectic reaction and at the end of solidification. Iron powder or carbonic material addition to the S- or O-bearing coating increases the undercooling degree, lowering both $\Delta \mathrm{T}_{1}$ and $\Delta \mathrm{T}_{3}$ (more negative), but the casting skin formation sensitivity decreases. 


\section{Conclusions}

The lowest eutectic temperature (TEU) is slightly increased by the O-bearing coating and decreased by the S-bearing coating, while carbonic material or iron powder supplementary addition leads to a visible TEU decrease.

The highest (recalescence) eutectic temperature TER is only increased a little bit by the O-bearing coating, but it is not affected by the S-bearing coating; the carbonic material visibly decreases TER for the O-bearing coating, but only at a limited level for the S-bearing coating, while the Fe-bearing coating visibly decreases TER for S-bearing coating application.

The temperature at the end of solidification TES is at a lower level for all the tested mold coating variants, compared to the uncoated mold solidification. Supplementary carbonic material or iron powder addition decreases the temperature of the end of solidification much more.

The O- or S-bearing coating had a limited effect on the graphite nodularity inside the casting, by reducing it, while the application of the carbonic material or iron powder acted in a positive manner. Better results are obtained by carbonic material addition on the O-bearing coating and iron powder on the S-bearing coating.

A surface layer at different graphite morphologies compared to the casting body is present, at a large range of thicknesses, from 50 up to $200 \mu \mathrm{m}$, with a higher level as metal matrix evaluation. The lowest thickness of the surface layer (skin) is obtained without mold coating, while O or S included in the mold coating increases the casting skin thickness, but at different powers: Up to $50 \%$ by oxygen and 2.5-3.3 times for sulfur action, respectively, despite that fact that, in the casting body, the graphite nodularity had a limited decrease.

Despite this, the mold coatings influence the solidification pattern not only by their thermal-physical properties (solidification cooling rate), but also as possible sources for active substances, supposed to be able to diffuse into the iron melt; to affect structure characteristics, the casting skin formation appears to be attributed mainly to the second influencing factor.

The negative role of oxygen and, especially, of sulfur in graphite degeneration in the surface casting layer could be counteracted by the addition of materials able to block the diffusion of these elements into the iron melt. It is found that carbonic material is more efficient at limiting oxygen negative effects, and iron powder is more efficient at limiting sulfur negative effects. More experiments are necessary to quantify their capacity to block the oxygen or sulfur transfer into the iron melt.

Author Contributions: D.A., M.C., S.S., I.S. and I.R. contributed equally in conceiving, designing and performing the experiments; analyzing the data; and writing the paper. All authors have read and agreed to the published version of the manuscript.

Funding: This research was funded by the Operational Programme Human Capital of the Ministry of European Funds through the Financial agreement 51668/09.07.2019, SMIS code 124705.

Conflicts of Interest: The authors declare no conflict of interest.

\section{References}

1. Boonmee, S.; Stefanescu, D.M. Occurrence and effect of casting skin in compacted graphite iron. Int. J. Cast. Met. Res. 2016, 29, 47-54. [CrossRef]

2. Baier, J.; Koppen, M. Incidence and Avoidance of Defects Attributable to Molding Sands. In Manual of Casting Defects; IKO: Erbsloh, Marl, Germany, 1994; pp. 32-35.

3. Marti, F.; Karsay, S.I. Localized flake graphite structure as a result of a reaction between molten ductile iron and some components of the mould. AFS Trans. 1979, 87, 221-226.

4. Xiaogan, H. Nodular Iron Surface Deterioration Due to PTSA in Resin. AFS Trans. 1992, 100, 9-15.

5. Bauer, W. Research on the Surface Graphite Generation in the Ductile Iron Casting in PTSA-Furan Resin Moulds. Giesserei Praxis 1982, 11, 175-183.

6. Boonmee, S.; Stefanescu, D.M. Casting skin management in compacted graphite iron. Part II: Mechanism of casting skin formation. AFS Trans. 2013, 121, 449-459. 
7. Quing, J.; Lekakh, S.; Richards, V. No-bake S-containing mold-DI metal interactions: Consequences and potential applications. AFS Trans. 2013, 121, 13-20.

8. Ivan, N.; Chisamera, M.; Riposan, I. Mg-bearing coating of resin sand-PTSA moulds to control graphite degeneration in the surface layer of ductile iron castings. Mater. Sci. Technol. 2012, 28, 1246-1253. [CrossRef]

9. Ivan, N.; Chisamera, M.; Riposan, I. Influence of magnesium content and coating type on graphite degeneration in surface layer of iron castings in resin sand-PTSA moulds. ISIJ Int. 2012, 52, 1848-1855. [CrossRef]

10. Ivan, N.; Chisamera, M.; Riposan, I. Mold coatings to reduce graphite degeneration in the surface layer of ductile Iron castings. Int. J. Metalcasting 2012, 6, 61-69. [CrossRef]

11. Ivan, N.; Chisamera, M.; Riposan, I. Graphite degeneration in the surface layer of ductile iron castings. Int. J. Cast Met. Res. 2013, 26, 138-142. [CrossRef]

12. Ivan, N.; Chisamera, M.; Riposan, I.; Stan, S. Control of graphite degeneration in the surface layer of Mg-treated iron castings in resin sand-P-Toluol Sulphonic Acid (PTSA) molds. AFS Trans. 2013, 121, 379-390.

13. Chisamera, M.; Ivan, N.; Riposan, I.; Stan, S. Iron casting skin management in no-bake mould-Effects of magnesium residual level and mould coating. China Foundry 2015, 12, 222-230.

14. QuiK-Cup®QuiK-Lab®E Thermal Analysis of Cast Iron. Available online: https://www.heraeus.com/media/ media/hen/doc_hen/measurement_instruments/quik-cup.pdf (accessed on 20 June 2020).

15. Anca, D. Research on the Loss Modifying Effect in the Superficial Layer Phenomenon of the Iron Castings. Ph.D. Thesis, POLITEHNICA University of Bucharest, Bucharest, Romania, 2014.

16. Thielemann, T. Zur Wirkung van Spurenelementen in Gusseisen mit Kugelgraphit. Giessereitechnik 1970, 16, 16-24.

17. Riposan, I.; Chisamera, M.; Stan, S.; White, D. Role of Residual Aluminium in Ductile Iron Solidification. AFS Trans. 2007, 115, 423-433.

18. Sillen, R.V. Optimizing inoculation practice by means of thermal analysis. In Proceedings of the AFS International Inoculation Conference, Rosemont, IL, USA, 6-8 April 1998.

19. Sillen, R.V. Novacast Technologies. 2006. Available online: www.novacast.se (accessed on 20 June 2020).

20. Leca, L.; Prisecaru, I. Thermophysical and Thermodynamical Properties; Editura Tehnica: Bucharest, Romania, 1994.

21. Riposan, I.; Skaland, T. Modification and inoculation of castiron. In Cast Iron Science and Technology Handbook; Stefanescu, D.M., Ed.; American Society of Materials: Cleveland, OH, USA, 2017; pp. 160-176.

22. Anca, D.; Chisamera, M.; Stan, S.; Riposan, I. Graphite degeneration in High Si, Mg-treated iron castings-Sulphur and oxygen addition effects. Int. J. Metalcasting 2019. [CrossRef]

23. Anca, D.; Chisamera, M.; Stan, S.; Riposan, I. Graphite degeneration in the superficial layer of high Si-ductile iron casting as influence of inoculation and protective coating against sulphur diffusion into the iron melt. J. Mater. Res. Technol. 2019, 8, 5160-5170. [CrossRef]

(C) 2020 by the authors. Licensee MDPI, Basel, Switzerland. This article is an open access article distributed under the terms and conditions of the Creative Commons Attribution (CC BY) license (http://creativecommons.org/licenses/by/4.0/). 